\title{
Perception of medical students to learning methods in internal medicine: A pilot survey from Northern Nigerian University
}

\author{
Aliyu Ibrahim, ${ }^{1}$ Musa Bello Kofar-Naisa ${ }^{2}$ \\ ${ }^{1}$ Neurology Unit, Department of Medicine, Faculty of Clinical Sciences, Bayero University Kano; \\ ${ }^{2}$ Rheumatology Unit, Department of Medicine, Aminu Kano Teaching Hospital, Bayero University Kano, \\ Nigeria
}

\begin{abstract}
Medical education aims to produce graduates who have knowledge and problem-solving skills with the professional attitude necessary to function as a doctor. We evaluated the perception of clinical medical students to their learning environment in internal medicine. A cross sectional study conducted during the intermediate clerkship posting on Medical students of Bayero University, Kano using a 20-item self-administered questionnaire adopted from the Dundee Ready Education Environment Measure (DREEM). The internal consistency of the questionnaire was calculated using the Cronbach's Alpha coefficient. Principal components analysis was used for data reduction and grouping using the varimax rotation method. One hundred and twenty clinical medical students of Bayero University, Kano participated in the study with a mean age $\pm \mathrm{SD}$ of the respondents was $23.6 \pm 2.3$ years. A higher proportion of the students $(60.8 \%)$ were males. The internal consistency of the 20 -items questionnaire was 0.82 measured using the Cronbach's Alpha coefficient. The mean perception score of the respondents to undergraduate learning environment in internal
\end{abstract}

Correspondence: Aliyu Ibrahim, Neurology Unit, Department of Medicine, Faculty of Clinical Sciences, Bayero University Kano, No 1 Zaria Road, PMB 3452, Kano-Nigeria.

Tel: +234.8037016608

E-mail: aliyubng@yahoo.com

Key words: Medical education, Learning, Perception.

Contributions: AI, concepts, design, definition of intellectual content, literature search, clinical studies, data acquisition, data analysis, statistical analysis, manuscript preparation, manuscript editing, manuscript review, guarantor; MBKN, literature search, clinical studies, data acquisition, data analysis, manuscript editing, manuscript review.

Conflict of interest: the authors declare no potential conflict of interest.

Funding: none.

Received for publication: 21 May 2018.

Revision received: 25 November 2018.

Accepted for publication: 25 November 2018.

This work is licensed under a Creative Commons Attribution NonCommercial 4.0 License (CC BY-NC 4.0).

(C) Copyright A. Ibrahim and M.B. Kofar-Naisa, 2018

Licensee PAGEPress, Italy

Annals of African Medical Research 2018; 1:21

doi:10.4081/aamr.2018.21 medicine was 42.3 (out of maximum of 60) which showed satisfaction with their learning environment. Perception of Male students was more positive compared to their female colleagues (43vs. 41, $\mathrm{P}=0.836$ ). Medical students perceived their learning environment in internal medicine as satisfactory, which buttress the need to further strengthen the curriculum, in order to prepare them for the enormous challenges of clinical practice.

\section{Introduction}

Medical education is an expensive venture and academic failure is wasteful to both society and the individual especially in resource-limited settings. Educational environment is one of the most important factors in determining the success of an effective curriculum. ${ }^{1}$ There has been growing interest and concern about the role of the learning environment in medical education as students' perception has been shown to be a useful measure for modifying and improving its quality. ${ }^{2}$ With increasing number of public and private degree awarding institutions in Nigeria, it is apt to adopt international standards with modifications to suit local needs. ${ }^{3,4}$ Periodic reviews in the medical curriculum and teaching methods are effective in improving the quality of training, which is lacking in most parts of the world, more so in countries located in Sub Saharan Africa. ${ }^{5}$ Medical school curricula in most developing countries are usually overloaded with knowledge that is delivered with little attempt to integrate the clinical disciplines and the basic sciences. ${ }^{6,7}$ The absence of a robust and coordinated medical education structure in line with current teaching trends for clinicians who have joined the Nigerian medical schools is also another major barrier to producing doctors with requisite knowledge and skills to respond to societal needs. ${ }^{8}$ Internal medicine is one of the core clinical subjects with three (3) clerkship postings in the Nigerian medical curricula, wherein the students learn to apply pathophysiologic principles they have acquired to signs and symptoms across all organ systems to arrive at a diagnosis, which will aid specific investigations, treatment and further management of possible complications of the disease upon completion. Previous reports have shown that Nigerian medical schools listed in the International Medical Education Directory (IMED), represent 21\% of all operating schools in sub-Saharan Africa. ${ }^{9}$ The report also showed that graduates from these medical schools who have migrated to the US or Canada though small in number, are able to provide patient care, with $80 \%$ serving as hospital staff or are in office-based practice. Most of them chose to specialize or practice in general internal medicine in suburban practice areas, where $25 \%$ or more of the population do not have a high school education or its equivalent. This goes to independently prove the acceptable foundation of Nigerian undergraduate medical education, despite the challenges of poorly motivated teachers, overstretched infrastructure and lack of modern teaching or assessment facilities. ${ }^{10}$ 
This study described the perception of undergraduate students to the training they receive in internal medicine, which would serve as a feedback template in a bid to improve and prepare them for the future challenges of clinical practice in resource challenged settings.

\section{Materials and Methods}

\section{Study design}

The study was a descriptive cross-sectional pilot survey conducted in the department of Internal Medicine. The study respondents were one hundred and twenty level 400 medical students that have completed their intermediate clerkship (Medicine 2) posting in the $2017 / 2018$ academic sessions, which served as the representative sample of clinical medical students of Bayero University Kano. Participation was entirely voluntary and systematic random sampling was done using their university registration number list. Every $2^{\text {nd }}$ student was selected after the first number was selected using the random number table. Dental students were excluded in the study, as their practice does not involve managing patients admitted into the medical wards after graduation.

\section{Study Protocol}

The 20-item semi structured self-administered questionnaire, which was a modification of the Dundee Ready Education Environment Measure (DREEM), a robust tool developed and validated for use regardless of culture and country. ${ }^{11}$ It has a section on demographics, perception of learning (in terms of the course preparation, lecture or tutorial presentation), perception of teachers (class and bedside management by lecturers) and perception of the examination. The questionnaire was administered at the end of the last lecture for the posting. The respondents took approximately 5minutes to complete the questionnaire in the lecture hall without consulting their colleagues to limit bias, which was ensured by the investigators.

The level of satisfaction was graded according to a 4-point Likert scale with strongly agree, agree, disagree and strongly disagree allotted 3,2, 1 and 0 marks respectively. This gave a total score range of 0 to 60 . Items that have a mean score of 2.3 or more are real positive points. Items with a mean of 1.3-2.2 have aspects that could be enhanced while any item with a mean of 1.2 or less indicate real negative points and should be examined more closely because they are problematic areas that need improvement.

\section{Data Analyses}

The completed questionnaires were entered onto Microsoft Excel 2013 spreadsheet. A random 10 per cent check of entered data done showed no transcription errors. The data was transferred and analysed using IBM SPSS Statistics software version 20.0 (SPSS Inc. IBM, Armonk, NY). Quantitative data were described as mean and standard deviation for normally distributed data, while categorical data was described as frequencies and percentages. Means between and within groups were compared using ttest for equality of means using Levene's test of equality of variances. Level of significance was based on a P-value of less than 0.05 .

\section{Reliability Test}

Internal consistency of the questionnaire was calculated using Cronbach's Alpha coefficient at an acceptable value $(0.7 \geq \alpha<0.8)$. Principal components analysis was done for data reduction and grouping the related variables into conceptually similar and statis- tically related groups. The extraction method was done using Varimax rotation method, with factors extracted based on an Eigenvalue of greater than 1. Kaiser-Meyer-Olkin (KMO) measure of sampling adequacy and Bartlett's test of sphericity were used with a cut off point for loading on each factor at 0.3 and $\mathrm{P}<0.001$ respectively. Percentage cut-off score for each domain was calculated using weighted-average quartile scores, where the $50^{\text {th }}$ percentile was accepted with respect to the student having either having a good or poor perception to undergraduate training in internal medicine.

\section{Results}

The mean age \pm SD of the respondents was $23.6 \pm 2.3$ years and the highest proportion (69.2\%) are between the ages of $20-24$ years. A higher proportion of the students $(60.8 \%)$ were males. The internal consistency of questionnaire was 0.82 measured using the Cronbach's Alpha score. The sample size for factor analysis was 20 items with 120 subjects. Kaiser-Meyer-Olkin measure of sampling adequacy was 0.77 . Bartlett's test of sphericity demonstrated a satisfactory suitability of the data to factor analysis $(\mathrm{P}<0.001)$ which showed that our variables were related and therefore suitable for structure detection. Extraction communalities estimates of the variance in each variable accounted for by the components were all above 0.48 to 0.79 . A loading cut-off greater than 0.30 was adopted and 7 factors were extracted. Each factor explained between 6.6 to $15.9 \%$ of the total variance. The seven factors extracted explained $64.6 \%$ of the total variance, revealing a strong factor structure. The mean perception score for the respondents was 42.3 (out of maximum of 60), which showed satisfaction with method of training in internal medicine. The study also showed areas of excellence (that is item scored $>2$ ) in 8-items. Eleven items have a mean score of 1.3 to 2.2 , and should be reviewed and improved upon. One item scored badly $(<1.2)$ indicating cause for concern in terms of students' perception of method of training in internal medicine. The items were the students showed strong agreement included; availability of course outline and bedside grouping at the beginning of the posting; invitation of questions from students by the lecturer during and after every lecture, bedside teaching or tutorial sessions, and decent dressing by lecturers. However, majority of them disagreed on the item on prompt marking and discussion of assignments given by the lecturers concerned, which has the lowest mean score (Table 1). Male students perceived a positive learning environment in the department of internal medicine when compared to their female counterparts (43.0 vs. 41.2, $\mathrm{P}=0.836$ ). However, no significant difference exists between the genders of the participants with the perception of the learning environment in internal medicine ( $t$-test of equality of means $=1.412, \mathrm{P}=0.161$ ). A one-way ANOVA conducted to evaluate null hypothesis showed no difference between the age of the students and perception of their learning environment in internal medicine based was also not statistically significant $\mathrm{F}(2,116)=$ $0.175, \mathrm{P}=0.913$. The assumption of homogeneity of variance was tested and found not to be tenable using Levene's statistic F $(2,116)$ $=0.683, \mathrm{P}=0.507$ (Table 2).

\section{Discussion and Conclusions}

The study showed medical students were satisfaction with the learning methods in the department of internal medicine by their high perception scores. This could possibly be explained by the use 
of the modified COBES curriculum, which is directed to increase student-centeredness in teaching, in keeping with the principle of the outcome-based medical education. ${ }^{12}$ It is a model that concentrates on equipping the graduate with knowledge, skills, and attitudes that are relevant to the host community. It also aims at training of doctors that have the ability to solve health problems based on the culture and traditions of the people, using available resources, in order to transform the image of the profession and make it more acceptable to them. Another possible explanation could be the introduction of a twice-weekly problem-based learning sessions as part of the teaching schedule, with special emphasis placed during their intermediate and senior clerkship postings. The students were given problem-based questions in the different specialties of internal medicine to solve in advance, which they subsequently present usually a day after to their tutors for correction and further discussions. This explanation was also reported from previous studies done in Europe and the Middle East. ${ }^{13,14}$ However, a study from Kuwait did not see any improvement in the perception score after implementing reforms in medical education using the problem based learning (PBL) curriculum. ${ }^{15}$

The study showed that the students were getting less than optimal feedback from their lecturers through the bedside teachings and discussion of marked assignments during their postings. This could be possibly be explained by the involvement of postgraduate resident doctors on rotation in the department with teaching of medical students especially tutorials and bedside teaching. This was similar to reports from Sweden where the medical students also perceived not receiving enough feedback and constructive criticism from their lecturers. ${ }^{16}$ In this instance, consideration may be given to staff development including resident doctors who partake in their teaching, creation of a cooperative and harmonious teacher-students' relationship, where opportunity to influence their education by bringing up relevant suggestions for further improvements is given. An optimal educational environment which foster and rewards educational leadership, innovation and excellence in teaching is also required. ${ }^{17}$ A Training of Trainers course on the basic concepts of the learning environment, small group teaching methods and feedback through formative and summative assessments should be mandatory for all newly appointed teaching staff to the medical school. ${ }^{2,18}$ Although, such courses are expensive and time consuming, funds need to be put aside to really actualize them in low resource setting.

Perception of the training environment in internal medicine by gender showed higher scores in the male students. This could be

Table 1. Itemized responses of medical students to learning environment in Internal Medicine.

\begin{tabular}{|c|c|c|c|c|c|}
\hline SN & Item (average score) & 0 & 1 & 2 & 3 \\
\hline$* 1$. & The course outline and bedside grouping is ready at the beginning of the posting (2.6) & $1(0.8)$ & $3(2.5)$ & $36(30.0)$ & $80(66.7)$ \\
\hline 2. & A lecture schedule \& tutorial list is given to students at the beginning of the posting (1.9) & $8(6.7)$ & $33(27.5)$ & $37(30.8)$ & $42(35.0)$ \\
\hline 3. & Lecturers enhance their lectures with materials and teaching aids to concretize the information (2.3) & $4(3.3)$ & $7(5.8)$ & $58(48.3)$ & $51(42.5)$ \\
\hline 4. & Student bedside teaching roster are made for the respective teams (1.9) & $8(6.7)$ & $33(27.5)$ & $47(39.2)$ & $32(26.7)$ \\
\hline 5. & It is easy to comprehend the information being disseminated by lecturers (2.2) & $0(0.0)$ & $9(7.5)$ & $73(60.8)$ & $38(31.7)$ \\
\hline 6. & Lectures \& tutorials are presented in an orderly sequence (2.0) & $3(2.5)$ & $25(20.8)$ & $66(55.0)$ & $26(21.7)$ \\
\hline 7. & Lecturers are punctual to class or bedside teaching (2.3) & $3(2.5)$ & 18(15.0) & $44(36.7)$ & $55(45.8)$ \\
\hline *8. & Questions are invited from students during and after every lecture or tutorial (2.5) & 2(1.7) & $3(2.5)$ & $46(38.3)$ & $69(57.5)$ \\
\hline$* * 9$ & Assignments given are marked promptly and discussed (1.2) & $22(18.3)$ & $62(51.7)$ & $27(22.5)$ & $9(7.5)$ \\
\hline 10. & Lecturers do not skip lectures or bedside teaching (2.1) & $7(5.8)$ & 21(17.5) & $51(42.5)$ & $41(34.2)$ \\
\hline 11. & Character of the lecturers is worthy of emulation (2.0) & $1(0.8)$ & $22(18.3)$ & $69(57.5)$ & 28(23.3) \\
\hline 12. & Lecturers dress decently (2.1) & $1(0.8)$ & $19(15.8)$ & $69(57.5)$ & $31(25.8)$ \\
\hline 13. & Lecturers do not distance themselves from students (1.4) & $8(6.7)$ & $60(50.0)$ & $43(35.8)$ & $9(7.5)$ \\
\hline 14. & Lecturers are able to maintain students discipline in the lecture room and ward (2.1) & $6(5.0)$ & $12(10.0)$ & $67(55.8)$ & $35(29.2)$ \\
\hline$* 15$ & Students feel free to contribute to discussion during lectures, tutorials or bedside teachings (2.6) & $1(0.8)$ & $2(1.7)$ & $39(32.5)$ & $78(65.0)$ \\
\hline 16. & Lecturers do not discriminate against any student in asking questions (2.3) & $2(1.7)$ & 14(11.7) & $51(42.5)$ & $53(44.2)$ \\
\hline$* 17$. & Student who gives the wrong answer is not jeered by the lecturer or students (2.6) & $1(0.8)$ & $3(2.5)$ & $43(35.8)$ & $73(60.8)$ \\
\hline 18. & All topics in the course outline are covered before the examination (2.1) & $5(4.2)$ & $16(13.3)$ & $60(50.0)$ & $39(32.5)$ \\
\hline 19. & Examination covers mainly the topics taught (2.3) & $1(0.8)$ & $8(6.7)$ & $64(53.3)$ & $47(39.2)$ \\
\hline 20. & Questions asked during the exams are explicit enough for comprehension (1.9) & $7(5.8)$ & $24(20.0)$ & $68(56.7)$ & 21(17.5) \\
\hline
\end{tabular}

Key: 0-Strongly Disagree, 1-Disagree, 2-Agree, 3-Strongly Agree; *Predominantly Agree, ${ }^{* * P r e d o m i n a n t l y ~ D i s a g r e e . ~}$

Table 2. Demographic characteristics of undergraduate students to learning in Internal medicine.

$\begin{array}{lllll}\text { Variable } & \text { Item } & \text { Mean (SD) } & \text { t-test } & \text { P-value } \\ \text { Gender } & \text { Male } & 43.1 \pm 6.8 & 1.412 & 0.161 \\ & \text { Female } & 41.2 \pm 7.1 & & 0.883 \\ \text { Age group } & 20-24 & 43.2 \pm 7.7 & 1.124 & \\ & 25-30 & 43.9 \pm 7.2 & & \\ & 30-34 & 44.0 \pm 5.9 & \text { Item } 9 \\ \text { Response } & \text { Negative } & <1.3 & \text { Items } 2,4,5,6,10,11,12,13,14,18 \text { and } 20 \\ & \text { Neutral } & 1.3-2.2 & \text { Items } 1,3,7,8,15,16,17 \text { and } 19 & \\ & \text { Positive } & \geq 2.3 & \end{array}$


attributed to satisfaction of the training atmosphere as more males were resident in the students' hostel making them more readily available for direct supervision of bedside drills and diagnostic procedures, even outside the scheduled teaching hours. This is similar to observations made in a report from India, ${ }^{19}$ which contrasted to reports from UK and Trinidad, ${ }^{2,20}$ where the investigators found higher scores in female students. Other studies have found no significant difference in terms of perception of the educational environment by gender. ${ }^{21,22}$

Our methods of evaluating perception of the educational environment in internal medicine should be interpreted within the context of it being a pilot cross sectional survey, where there is no association between cause and effect. Furthermore, the perception scores may not be generalizable to other students especially in lower classes, because of significant differences observed in relation to number of years spent in the MBBS programme. Despite these limitations, our analysis has several advantages, of being the first of its kind in a Northern Nigerian Medical school. It will serve as a good feedback template to lecturers on how their medical students perceive their training environment on a regular basis. The results can also be used to guide strategic planning for further researches on the subject of reforms in medical education in the country.

\section{References}

1. Stabback P. What Makes a Quality Curriculum? In-Progress Reflection No. 2 on" Current and Critical Issues in Curriculum and Learning". UNESCO International Bureau of Education. 2016.

2. Dunne F, McAleer S, Roff S. Assessment of the undergraduate medical education environment in a large UK medical school. Health Educ J 2006;65:149-58.

3. Rizwan M, Rosson N, Tackett S, Hassoun H. Opportunities and challenges in the current era of global medical education. Int J Med Educ 2018;9:111-2.

4. Shehnaz SI. Privatisation of medical education: viewpoints with a global perspective. Sultan Qaboos Univ Med J 2010;10:6.

5. Ibrahim M. Medical education in Nigeria. Medical teacher 2007;29:901-5.

6. Yamani N RM. The core curriculum and integration in medical education. Res Dev Med Educ 2016;5:50-4.

7. Quintero GA, Vergel J, Arredondo M, et al. Integrated medical curriculum: advantages and disadvantages. J Med Educ Curr Dev2016;3:S18920.
8. Malu AO. Universities and medical education in Nigeria. Niger Med J 2010;51:84-8.

9. IMED. Philadelphia, PA, USA: Foundation for Advancement of International Medical Education and Research (FAIMER); 2014 [cited 2018 5/11]; Available from: http://www.faimer.org/ resources/imed.html. .

10. Ezeanolue B. Current challenges in medical education in Nigeria. Int J Med Health Dev 2011;16:77-83.

11. Roff S, McAleer S, Ifere O, Bhattacharya S. A global diagnostic tool for measuring educational environment: comparing Nigeria and Nepal. Med Teach 2001;23:378-82.

12. Olopade FE, Adaramoye OA, Raji Y, et al. Developing a competency-based medical education curriculum for the core basic medical sciences in an African Medical School. Adv Med Educ Pract 2016;7:389.

13. Miles S, Leinster SJ. Medical students' perceptions of their educational environment: expected versus actual perceptions. Med Educ 2007;41:265-72.

14. Al-Mohaimeed A. Perceptions of the educational environment of a new medical school, Saudi Arabia. Int J Health Sci 2013;7:150.

15. Bouhaimed M, Thalib L, Doi SA. Perception of the educational environment by medical students undergoing a curricular transition in Kuwait. Med Princ Pract 2009;18:204-8.

16. Jakobsson U, Danielsen N, Edgren G. Psychometric evaluation of the Dundee ready educational environment measure: Swedish version. Med Teach2011;33:e267-e74.

17. Hongkan W, Arora R, Muenpa R, Chamnan P. Perception of educational environment among medical students in Thailand. Int J Med Educ 2018;9:18.

18. Asani M. Assessment methods in undergraduate medical schools. Nig J Basic Clin Sci 2012;9:53.

19. Mayya S, Roff S. Students' perceptions of educational environment: a comparison of academic achievers and underachievers at Kasturba Medical College, India. Educ Health 2004;17:280-91.

20. Bassaw B, Roff S, McAleer S, et al. Students' perspectives on the educational environment, Faculty of Medical Sciences, Trinidad. Med Teach 2003;25:522-6.

21. Abraham R, Ramnarayan K, Vinod P, Torke S. Students' perceptions of learning environment in an Indian medical school. BMC Med Educ 2008;8:20.

22. Soliman MM, Sattar K, Alnassar S, et al. Medical students' perception of the learning environment at King saud University Medical college, Saudi Arabia, using DREEM inventory. Adv Med Educ Pract 2017;8:221. 